\title{
Penerapan Good University Governance terhadap Kepuasan Mahasiswa dengan Excellent Service sebagai Variabel Moderasi
}

\author{
Kadek Eti Putrika ${ }^{1}$ \\ Fakultas Ekonomi dan Bisnis \\ Universitas Udayana, Indonesia
}

\author{
I Gusti Ayu Made Asri Dwija Putri1 \\ Fakultas Ekonomi dan Bisnis \\ Universitas Udayana, Indonesia
}

\begin{abstract}
Surel: etiputrika774@gmail.com
ABSTRAK

Penelitian bertujuan untuk mengetahui sejauh mana pengaruh penerapan good university governance, excellent service dalam meningkatkan kepuasan mahasiswa pada Fakultas Ekonomi Dan Bisnis Universitas Udayana. Responden sejumlah 100 orang yang merupakan anggota dari salah satu lembaga mahasiswa di lingkungan Fakultas Ekonomi Dan Bisnis Universitas Udayana. Metode pengambilan sampel dalam penelitian ini menggunakan purposive sampling. Teknik analisis data yang di gunakan Moderated Regression Analysis (MRA). Hasil analisis terdapat hubungan antara good university governance terhadap kepuasan mahasiswa. Terdapat hubungan antara excellent service terhadap kepuasan mahasiswa. Excellent service memperkuat pengaruh good university governance terhadapkepuasan mahasiswa.
\end{abstract}

Kata Kunci: Good University Governance; Excellent Service; Kepuasan.

\section{Implementation of Good University Governance on} Student Satisfaction with Excellent Service as Moderating Variable

\section{ABSTRACT}

This study aims to determine the extent of the influence of the implementation of good university governance, excellent service in increasing student satisfaction at the Faculty of Economics and Business, Udayana University. Respondents were 100 people who were members of one of the student institutions within the Faculty of Economics and Business, Udayana University. The sampling methodin this study used purposive sampling. The data analysis technique used is Moderated Regression Analysis (MRA). The results of the analysis show that there is a relationship between good university governance and student satisfaction. There is a relationship between excellent service and student satisfaction. Excellent service strengthens the influence of good university governance on student satisfaction.

Keywords: Good University Governance; Excellent Service; Satisfaction.

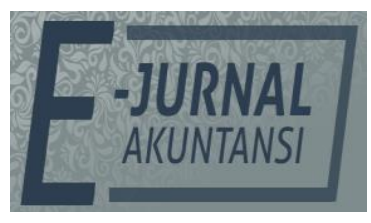

e-ISSN 2302-8556

Vol. 31 No. 11

Denpasar, November 2021

Hal. 2693-2703

DOI:

10.24843/EJA.2021.v31.i11.p02

PENGUTIPAN:

Putrika, K. E., \& Putri, I. G. A. M. A. D. (2021). Penerapan Good University Governance terhadap Kepuasan Mahasiswa dengan Excellent Service sebagai Variabel Moderasi. E-Jurnal Akuntansi, $31(11), 2693-2703$

RIWAYAT ARTIKEL:

Artikel Masuk: 26 Oktober 2020 Artikel Diterima: 19 Februari 2021

Artikel dapat diakses: https:/ / ojs.unud.ac.id/index.php/Akuntansi/index 


\section{PENDAHULUAN}

Upaya yang dapat ditempuh untuk meningkatkan mutu perguruan tinggi dapat dilakukan dengan memberikan pelayanan prima (excellent service) kepada masyarakat khususnya mahasiswa. Pelayanan prima yang dimaksudkan disini adalah melakukan pelayanan yang sebaik mungkin agar pelanggan (mahasiswa) merasa puas. Dengan menerapkan excellent service, perguruan tingi dapat menumbuhkan rasa kepercayaan masyaraka terhadap perguruan tinggi yang bersangkutan yaitu Fakultas Ekonomi dan Bisnis Universitas Udayana. Untuk bertahan dalam industri layanan yang kompetitif, perusahaan harus mengembangkan strategi baru untuk membuat pelanggannya puas. Membangun loyalitas pelanggan bukanlah suatu pilihan dalam bisnis, ini adalah satu-satunya cara untuk mengembangkan keunggulan kompetitif yang berkelanjutan (Jamaluddin \& Ruswanti, 2017).

Fakultas Ekonomi dan Bisnis Universitas Udayana daalam menghadapi daya saing yang tinggi, harus memiliki standar mutu yang lebih dikembangkan dalam operasionalnya, sehingga keberlangsungan lembaga tetap dapat dipertahankan. Dengan kata lain Fakultas Ekonomi dan Bisnis Universitas Udayana harus lebih maksimal lagi dalam meningkatkan mutu yang dimilikinya, karena dengan peningkatan mutu maka citra dari lembaga ini akan tetap baik di mata para pengguna jasa pendidikan (stakeholders).

Keberhasilan yang dapat mendukung Fakultas Ekonomi dan Bisnis Universitas Udayana untuk meningkatkan mutu dapat dilakukan dengan peningkatan layanan akademik kepada mahasiswa serta memberikan fasilitas yang mendukung dalam proses belajar. Maka dari itu pentingnya pelayanan menjadi salah satu faktor keberhasilan institusi pendididikan sebagai sebuah organisasi publik. Universitas telah menjadi situs utama pengetahuan tata kelola sejauh itu adalah badan perusahaan yang melegitimasi diri yang sebagian besar menggunakan pengetahuan yang dihasilkan (Delanty, 2002).

Kualitas pelayanan kepada mahasiswa dapat ditingkatkan dengan menerapkan tata kelola perguruan tinggi yang baik atau good university governance. Konsep GUG muncul akibat dari berbagai masalah pengelolaan perguruan tinggi. Dari masalah administrasi hingga korupsi (Larasati et al., 2018). Selain itu konsep ini juga terlahir dari kesadaran bahwa penyelenggaraan pendidikan tinggi dan institusi perguruan tinggi berbeda dengan penyelenggaraan sebuah Negara ataupun korporasi, yang menjadi pembedanya adalah nilai-nilai luhur dari pendidikan harus tetap dijaga dalam pelaksanaanya. Dengan demikian, maka dapat ditentukan suatu ukuran apakah suatu perguruan tinggi telah menerapkan GUG atau tidak adalah sampai sejauhmana perguruan tinggi tersebut mampu menyikapi dinamika yang terjadi dalam penyelenggaraannya tanpa mengkhianati nilai-nilai luhur tadi dan amanat yang diembannya dari masyarakat, bangsa dan negara yang menaunginya (Rahayu \& Wahab, 2013). Penerapan tata kelola yang baik di universitas diharapkan dapat meningkatkan nilai tambah bagi semua pemangku kepentingan (Hanifah, 2018). Untuk relevansi tata kelola perusahaan, dan khususnya dewan direksi, dalam masyarakat kita, sangat terbuka untuk memiliki publikasi baru tentang topik terkait (Zattoni, 2007).

Good University Governance (GUG) merupakan turunan dari teori Good Corporate Governance yang merupakan konsep yang memiliki prinsip-prinsip yang 
dapat menjadi tolak ukur kinerja suatu perusahaan. Penerapan tata kelola perguruan tinggi yang baik (good university governance) secara konsisten dan berkesinambungan dapat meningkatkan budaya mutu serta pelayanan akademik dan non akademik sebuah perguruan tinggi sehingga diharapkan dapat berkontribusi pada pencitraan yang positif, reputasi yang unggul dan kualitas daya saing yang tinggi (Rosyid et al., 2015).

Good Corporate Governance atau tata kelola perusahaan yang baik merupakan pedoman yang sangat efektif digunakan oleh suatu perusahaan untuk meningkatkan daya saing serta menciptakan pedoman pengelolaan. Agar suatu organisasi/perusahaan bisa hidup berkelanjutan, organisasi harus bisa hidup selaras atau menyesuaikan diri dengan lingkungan eksternal sehingga tujuan perusahaan secara umum dapat dicapai (Putri, 2012). Arisman (2016) menyatakan bahwa Good Corporate Governance merupakan system mengenai bagaimana suatu organisasi dikelola dan di kendalikan. prinsip-prinsip tata kelola organisasi yang baik mencakup prinsip-prinsip administrasi layanan, publisitas, dan transparansi (Ryynänen \& Harisalo, 2018). Struktur tata kelola perusahaan adalah bagian penting dari perusahaan modern dan bagian penting dari perusahaan (Zou, 2019).

Good University Governance adalah konsep yang lahir dari kesadaran bahwa penyelenggaraan pendidikan tinggi dan institusi perguruan tinggi berbeda dengan penyelenggaraan sebuah Negara ataupun korporasi, yang menjadi pembedanya adalah nilai-nilai luhur dari pendidikan harus tetap dijaga dalam pelaksanaanya. Dengan demikian, maka dapat ditentukan suatu ukuran apakah suatu perguruan tinggi telah menerapkan GUG atau tidak adalah sampai sejauhmana perguruan tinggi tersebut mampu menyikapi dinamika yang terjadi dalam penyelenggaraannya tanpa mengkhianati nilai-nilai luhur tadi dan amanat yang diembannya dari masyarakat, bangsa dan negara yang menaunginya (Rahayu \& Wahab, 2013). Penerapan tata kelola yang baik di universitas diharapkan dapat meningkatkan nilai tambah bagi semua pemangku kepentingan (Hanifah, 2018). Untuk relevansi tata kelola perusahaan, dan khususnya dewan direksi, dalam masyarakat kita, sangat terbuka untuk memiliki publikasi baru tentang topik terkait (Zattoni, 2007).

Prinsip-prinsip good university governance menurut Directorate of Institutional and Cooperation Ditjen Dikti Kemdikbud (2014) antara lain transparency (keterbukaan), accountability (akuntabilitas), Responsibility (responsibilitas), independency (independensi), dan fairness (kewajaran dan kesetaraan), penjaminan mutu dan relevansi, efektifitas dan efisiensi, dan nirlaba. Prinsip GCG dibutuhkan agar tercapainya kesinambungan usaha (sustainability) perusahaan dengan memperhatikan stakeholder (KNKG,2006). Hal ini terkait dengan hubungan antara tata kelola perusahaan dan tata kelola aset utama perusahaan di perusahaan swasta dan organisasi publik (Juiz et al., 2014).

Dengan adanya penerapan Good University Governance (GUG) mampu mebantu dalam hal perbaikan mutu perguruan tinggi. Fakultas ekonomi dan bisnis memberikan fasilitas yang lengkap kepada mahasiswa, namun terkadang masih terdapat beberapa kekurangan yang harus terus di perbaiki seperti keadaan air toilet yang sering mati, Wi-Fi yang tidak terjangkau ke seluruh kelas, LCD proyektor yang rusak di beberapa kelas, dosen yang hanya menyuruh membuat ringkasan tanpa menjelaskan, tidak ada konfirmasi mengenai kehadiran dosen, 
pegawai yang terkadang mengabaikan mahasiswa, jam istirahat pegawai yang tidak sesuai dsd.

Berdasarkan hasil penelitian dari (Lamadjido, 2012) menjelaskan bahwa semua variabel independen berpengaruh dengan variabel dependen. Transparansi berpengaruh terhadap kepuasan Pasien. Akuntabilitas berpengaruh terhadap kepuasan pasien. Partisipasi berpengaruh terhadap kepuasan Pasien. Keadilan berpengaruh terhadap kepuasan Pasien. Kesimpulannya adalah akuntabilitas merupakan variabel yang paling berpengaruh terhadap kepuasan pasien. Berdasarkan hasil penelitian Widjajanti \& Sugiyanto (2015) menunjukkan bahwa GUG berpengaruh positif signifikan terhadap excellent service dan excellent service berpengaruh positif signifikan terhadap trust. GUG secara langsung tidak berpengaruh terhadap trust. Hal ini berarti bahwa pelaksanaan tata kelola universitas yang baik (GUG) tidak dapat langsung memberikan kepercayaan (trust) terhadap mahasiswa tanpa adanya bukti nyata yang dapat dirasakan yaitu pelayanan yang prima (excellent service). Mengacu pada riset riset di telah disampaikan menarik bagi peneliti untuk diteliti mengenai sejauh mana keberhasilan pengaruh penerapan good university governance, excellent service di Fakultas Ekonomi dan Bisnis Universitas Udayana untuk menilai tingkat kepuasan yang dirasakan oleh mahasiswa, yang dimana nantinya dapat menjadi fokus perbaikan pelayanan bagi Fakultas Ekonomi dan Bisnis Universitas Udayana.

Good University Governance (GUC) bertujuan untuk mewujudkan Perguruan Tinggi yang akun Tabel. Penerapan Good Corporate Governance (GCG) pada perusahaan merupakan suatu konsep yang digunakan guna menjaga konsistensi dan kepercayaan serta menghasilkan kepuasan masyarakat terhadap perusahaan. Kuncaraningsih \& Ridla (2015) mengungkapkan bahwa semakin tinggi tingkat Good Corporate Governance maka tingkat kepuasan muzakki juga akan semakin tinggi, dan bila tingkat Good Corporate Governance menurun juga akan berdampak penurunan pada kepuasan muzakki. Surya dalam Dalimunthe (2010) menjelaskan bahwa mutu dan kualitas pelayanan menjadi lebih baik dan memuaskan dan tidak menimbulkan keluhan masyarakat dalam menerima pelayanan setelah adanya penerapan prinsip-prinsip Good Corporate Governance.

Hasil penelitian dari Lamadjido (2012) menjelaskan bahwa semua variabel independen berpengaruh dengan variabel dependen. Transparansi berpengaruh terhadap kepuasan Pasien. Akuntabilitas berpengaruh terhadap kepuasan Pasien. Partisipasi berpengaruh terhadap kepuasan Pasien. Keadilan berpengaruh terhadap kepuasan Pasien. Kesimpulannya adalah akuntabilitas merupakan variabel yang paling berpengaruh terhadap kepuasan pasien.

$\mathrm{H}_{1}$ : Pengaruh antara good university governance terhadap kepuasan mahasiswa.

Pelayanan prima adalah kegiatan untuk memberikan nilai tambah agar dapat memenuhi atau melampaui harapan pelanggan. Pelayanan prima merupakan terjemahan istilah "excellent service" yang secara harfiah berarti pelayanan terbaik atau sangat baik. Disebut sangat baik atau terbaik karena sesuai dengan standar pelayanan yang berlaku atau dimiliki instansi pemberi pelayanan. Berdasarkan teori yang telah dijabarkan tingkat kepuasan merupakan fungsi dari perbedaan antara kinerja yang ia rasakan dan harapan. 
Hasil penelitian dari Silvia (2012) menunjukkan bahwa kepuasan pelanggan di Kantor Pelayanan Perbendaharaan Negara (KPPN) Makassar II dipengaruhi oleh faktor pelayanan prima. (Ferlinda et al., 2018) dari penelitian implementasi Good Corporate Governance dalam meningkatkan kualitas pelayanan pada PT Telkom Banyuwangi, dapat menarik kesimpulan bahwa Good Corporate Governance telah dilaksanakan dengan baik sesuai penguatan prinsip penerapan nilai perusahaan (corporate values) untuk meningkatkan kualitas pelayanan. $\mathrm{H}_{2}$ : Pengaruh antara Excellent Service terhadap Kepuasan Mahasiswa.

Penerapan prinsip-prinsip Good University Governance (GUG) dalam pengelolaan pelayanan menjadi suatu tuntutan utama terhadap peningkatan kinerja pelayanan yang dimana nantinya akan mampu meningkatkan kepuasan pelanggan. Hasil penelitian dari (Widjajanti \& Sugiyanto, 2015a) menunjukkan bahwa secara garis besar masyarakat menilai implementasi dari good governance dan gaya kepemimpinan di lingkungan Dinperindag telah dinilai baik, yang dimana memperoleh hasil pelaksanaan prinsip good governance dapat menciptakan excellent service untuk selanjutnya membawa kepercayaan terhadap masyarakat.

$\mathrm{H}_{3}$ : Pengaruh antara Good University Governance terhadap Kepuasan Mahasiswa dengan Excellent Service sebagai Variabel Moderasi.

\section{METODE PENELITIAN}

Lokasi penelitian adalah tempat atau wilayah dimana penelitian akan dilakukan. Penelitian ini dilakukan di lingkungan Fakultas Ekonomi dan Bisnis Universitas Udayana. Populasi dalam penelitian ini adalah mahasiswa Fakultas Ekonomi dan Bisnis Universitas Udayana dengan kriteria telah menempuh minimal tiga semester serta tergabung dalam organisasi kemahasiswaan. Metode pengambilan sampel dalam penelitian ini menggunakan purposive sampling. Teknik analisis data yang digunakan dalam penelitian ini adalah Moderated Regression Analysis (MRA). Sebelum dilakukan Moderated Regression Analysis (MRA). Model regresi dalam penelitian ini ditunjukan dengan persamaan sebagai berikut.

Keterangan:

$$
Y=\alpha+\beta_{1} X_{1}+\beta_{2} X_{2}+\beta_{3}\left(X_{1} X_{2}\right)+\varepsilon
$$

$$
\begin{array}{ll}
Y & =\text { Kepuasan Mahasiswa } \\
\mathrm{a} & =\text { Konstanta } \\
\beta_{1}-\beta_{3} & =\text { Koefisien } \\
X_{1} & =\text { Good University Governance } \\
X_{2} & =\text { Excellence Service } \\
\varepsilon \quad=\text { error term }
\end{array}
$$

\section{HASIL DAN PEMBAHASAN}

Uji normalitas bertujuan untuk menguji apakah dalam model regresi, variabel penganggu atau residual memiliki distribusi normal. Model regresi yang baik adalah data yang terdistribusi normal. Uji statistik yang digunakan untuk uji normalitas data dalam penelitian ini adalah uji Kolmogorov-Smirnov. Data yang dihasilkan dinyatakan berdistribusi normal apabila signifikansi Iebih besar dari 0,05 . 
Tabel 1. Hasil Uji Normalitas

\begin{tabular}{llc}
\hline & One-Sample Kolmogorov-Smirnov Test & Unstandardized Residual \\
\hline $\mathrm{N}$ & & 100 \\
Normal Parametersa,b & Mean & $0 \mathrm{E}-7$ \\
& Std. Deviation & 1,51256391 \\
Most Extreme Differences & Absolute & 0,084 \\
& Positive & 0,051 \\
& Negative & $-0,084$ \\
Test Statistic & & 0,839 \\
Asymp.Sig.(2-tailed) & & 0,482 \\
\hline
\end{tabular}

Sumber: Data Penelitian, 2020

Berdasarkan Tabel 1, dapat dilihat bahwa nilai Kolmogorov Sminarnov (K-S) sebesar 0,839 dan nilai Asymp Sig (2-tailed) sebesar 0,482, hasil tersebut mengindikasikan bahwa model persamaan regresi tersebut berdistribusi normal karena nilai Asymp Sig (2-tailed) lebih besar dari nilai alpha 0,05 (0,482 > 0,05).

Uji multikolinearitas yaitu suatu pengujian yang bertujuan untuk mengetahui apakah model regresi ditemukan adanya korelasi antar variabel bebas (independen). Model regresi yang baik seharusnya tidak mengandung korelasi antara variabel bebas. Pengujian ini ditentukan oleh nilai tolerance atau variance inflation faktor (VIF), jika nilai torelance lebih dari atau sama dengan $10 \%(20,10)$ atau nilai Variance Inflation Factor (VIF) kurang dari atau sama dengan 10 (S10), maka tidak terjadi multikolonieritas (Ghozali, 2016).

Tabel 2. Hasil Uji Multikolinieritas

\begin{tabular}{|c|c|c|c|}
\hline \multicolumn{4}{|c|}{ Coefficients $^{a}$} \\
\hline & \multirow{2}{*}{ Model } & \multicolumn{2}{|c|}{ Collinearity Statistics } \\
\hline & & Tolerance & VIF \\
\hline \multirow[t]{3}{*}{$\overline{1}$} & Good University Governance & 0,222 & 4,508 \\
\hline & Excellent Service & 0,163 & 6,141 \\
\hline & Good University Governance*Excellent Service & 0,189 & 5,198 \\
\hline
\end{tabular}

Sumber: Data Penelitian, 2020

Berdasarkan Tabel 2, didapat bahwa variabel Good University Governance memiliki tolerance lebih besar dari 0,1 $(0,222>0,1)$ dan VIF lebih kecil dari 10 $(4,508<10)$. Variabel Excellent Service memiliki tolerance lebih besar dari 0,1 $(0,163$ $>0,1)$ dan VIF lebih kecil dari $10(6,141<10)$, variabel Good University Governance dengan moderasi Excellent Service memiliki tolerance lebih besar dari 0,1 (0,189> $0,1)$ dan VIF lebih kecil dari $10(5,198<10)$. Dengan demikian dapat dinyakatakan tidak terjadi multikolinieritas.

Uji heteroskedastisias bertujuan untuk menguji apakah dalam model regresi terjadi ketidaksamaan variance dari residual satu pengamatan ke pengamatan yang lain. Pada penelitian ini pengujian heteroskedastisitas dilakukan dengan menggunakan uji Glejser. Uji Glejser adalah meregresi masing-masing variabel independen dengan absolut residual sebagai variabel independennya. Apabila probabilitas signifikansinya diatas tingkat kepercayaan $5 \%(0,05)$, maka dapat disimpulkan model regresi tidak mengandung adanya heteroskedastisitas. 
Tabel 3. Hasil Uji Heteroskedastisitas

\begin{tabular}{|c|c|c|c|c|c|}
\hline \multirow[t]{2}{*}{ Model } & \multicolumn{2}{|c|}{$\begin{array}{l}\text { Unstandardized } \\
\text { Coefficients }\end{array}$} & \multirow{2}{*}{$\begin{array}{c}\begin{array}{c}\text { Standardized } \\
\text { Coefficients }\end{array} \\
\text { Beta }\end{array}$} & \multirow[t]{2}{*}{$\mathrm{t}$} & \multirow[t]{2}{*}{ Sig. } \\
\hline & $\mathrm{B}$ & Std. Error & & & \\
\hline$\overline{1}$ (Constant) & 2,166 & 1,140 & & 1,899 & 0,061 \\
\hline Good University Governance & $-0,054$ & 0,029 & $-0,396$ & $-1,867$ & 0,065 \\
\hline Excellent Service & 0,005 & 0,022 & 0,059 & 0,239 & 0,812 \\
\hline $\begin{array}{l}\text { Good University } \\
\text { Governance* Excellent Service }\end{array}$ & 0,000 & 0,000 & 0,317 & 0,947 & 0,346 \\
\hline
\end{tabular}
Sumber: Data Penelitian, 2020

Pada Tabel 3, dapat dilihat bahwa nilai signifikansi dari variabel Good University Governance sebesar 0,065. Nilai signifikansi dari variabel Excellent Service sebesar 0,812. Nilai signifikansi dari variabel Good University Governance dengan Excellent Service sebagai pemoderasi sebesar 0,346. Nilai tersebut lebih besar dari 0,05 yang berarti tidak terdapat pengaruh antara variabel bebas terhadap absolute residual. Dengan demikian, model yang dibuat tidak mengandung gejala heteroskedastisitas. MRA merupakan aplikasi khusus regresi linear berganda, dimana dalam persamaan regresinya mengandung unsur interaksi (perkalian dua atau lebih variabel independen). Uji analisis koefisien regresi akan menggunakan uji Moderated Regression Analysis (MRA). Memilih MRA dalam penelitian ini menjelaskan variabel pemoderasi dalam memperkuat atau memperlemah hubungan antara variabel independen dan dependen.

Tabel 4. Hasil Analisis MRA (Moderated Regression Analysis)

\begin{tabular}{|c|c|c|c|c|c|c|}
\hline \multirow{2}{*}{\multicolumn{2}{|c|}{ Model }} & \multicolumn{2}{|c|}{$\begin{array}{l}\text { Unstandardized } \\
\text { Coefficients }\end{array}$} & \multirow{2}{*}{$\begin{array}{c}\begin{array}{c}\text { Standardized } \\
\text { Coefficients }\end{array} \\
\text { Beta }\end{array}$} & \multirow[t]{2}{*}{$\mathrm{t}$} & \multirow[t]{2}{*}{ Sig. } \\
\hline & & B & Std. Error & & & \\
\hline \multirow[t]{4}{*}{$\overline{1}$} & (Constant) & $-1,335$ & 2,010 & & $-0,664$ & 0,508 \\
\hline & Good University Governance & 0,127 & 0,051 & 0,252 & 2,469 & 0,015 \\
\hline & Excellent Service & 0,102 & 0,039 & 0,312 & 2,619 & 0,010 \\
\hline & $\begin{array}{l}\text { Good University Governance Excellent } \\
\text { Service }\end{array}$ & 0,001 & 0,001 & 0,362 & 2,251 & 0,027 \\
\hline
\end{tabular}

Sumber: Data Penelitian, 2020

Berdasarkan hasil analisis MRA seperti yang disajikan pada Tabel 4, maka dapat dibuat persamaan struktural sebagai berikut:

$$
\mathrm{Y}=-1,335+0,127 \mathrm{X}+0,102 \mathrm{M}+0,001 \mathrm{XM}
$$

Nilai konstanta diasumsikan bahwa tanpa ditambahkan variabel Good University Governance dan Excellent Service maka nilai kepuasan mahasiswa sebesar -1,335. Apabila X (Good University Governance) mengalami peningkatan sebesar 1 satuan dengan asumsi Excellent Service dianggap tetap maka kepuasan mahasiswa akan meningkat sebesar 0,127 satuan. Apabila M (Excellent Service) mengalami peningkatan sebesar 1 satuan dengan asumsi Good University Governance dianggap tetap maka kepuasan mahasiswa akan meningkat sebesar 0,102 satuan. Apabila XM (Good University Governance dengan Excellent Service sebagai pemoderasi) mengalami peningkatan sebesar 1 satuan maka kinerja karyawan akan meningkat sebesar 0,001 satuan.

Berdasarkan nilai $\mathrm{R}^{2}$ dapat diketahui berapa persen variabel dependen dapat dijelaskan oleh variabel independen, sedangkan sisanya dipengaruhi atau dijelaskan oleh variabel lain yang tidak dimasukan dalam model penelitian. Nilai 
adjusted $\mathrm{R}^{2}$ dapat naik atau turun apabila satu variabel independen ditambahkan ke dalam model.

Tabel 5. Hasil Analisis Koefisien Determinasi

\begin{tabular}{ccccc}
\hline Model & $\mathrm{R}$ & $R$ Square & Adjusted $R$ Square & $\begin{array}{c}\text { Std. Error of the } \\
\text { Estimate }\end{array}$ \\
\hline 1 & $0,882^{\mathrm{a}}$ & 0,778 & 0,771 & 1,536 \\
\hline
\end{tabular}

Sumber: Data Penelitian, 2020

Berdasarkan Tabel 5, besarnya pengaruh variabel bebas terhadap variabel terikat yang ditunjukkan oleh nilai determinasi total (Adjused $R$ Square) sebesar 0,771 mempunyai arti bahwa sebesar 77,1\% variasi Good University Governance dan Excellent Service sebagai pemoderasi terhadap kepuasan mahasiswa, sedangkan sisanya sebesar $22,9 \%$ dijelaskan oleh faktor lain yang tidak dimasukkan ke dalam model. Uji statistik F ini digunakan untuk menilai kelayakan model penelitian. Pada dasarnya uji $\mathrm{F}$ ini bertujuan untuk melihat apakah semua variabel independen atau bebas yang dimaksud dalam model mempunyai pengaruh secara serempak terhadap variabel dependen atau terikat. Tingkat signifkan masing- masing variabel bebas dengan $\alpha=0,05$. Apabila tingkat signifikansi $F<a$ $=0,05$ maka model ini dapat dikatakan layak uji. Sebaliknya tingkat signifikansi $\mathrm{F}$ $\geq a=0,05$ maka model persamaan regresi dapat dikatakan tidak layak uji.

Tabel 6. Hasil Uji Kelayakan Model (Uji F)

\begin{tabular}{|c|c|c|c|c|c|c|}
\hline & Model & Sum of Squares & $\mathrm{df}$ & Mean Square & $\mathrm{F}$ & Sig. \\
\hline \multirow[t]{3}{*}{1} & Regression & 794,013 & 3 & 264,671 & 112,180 & $0,000^{\mathrm{b}}$ \\
\hline & Residual & 226,497 & 96 & 2,359 & & \\
\hline & Total & 1020,510 & 99 & & & \\
\hline
\end{tabular}

Sumber: Data Penelitian, 2020

Berdasarkan Tabel 6, dapat dilihat nilai signifikan sebesar 0,000 kurang dari $0,05(0,000<0,05)$ sehingga model dalam penelitian ini layak atau variabel bebas mampu menjelaskan variabel terikat, dengan kata lain variabel independen secara simultan atau bersama berpengaruh terhadap variabel dependen. Uji statistik $t$ pada dasarnya menunjukkan seberapa jauh pengaruh satu variabel penjelas atau independen secara individual dalam menerangkan variasi variabel dependen. Apabila nilai probabilitas signifikansi $\leq 0,05$ maka secara parsial terdapat pengaruh signifkan variabel bebas terhadap variabel terikat, jika nilai probabilitas signifikan >0,05 maka secara parsial tidak terdapat pengaruh yang signifikan antara variabel bebas terhadap variabel terikat.

Tabel 7. Hasil Uji Hipotesis (Uji t)

\begin{tabular}{llccccc}
\hline \multirow{2}{*}{ Model } & \multicolumn{2}{c}{$\begin{array}{c}\text { Unstandardized } \\
\text { Coefficients }\end{array}$} & $\begin{array}{c}\text { Standardized } \\
\text { Coefficients }\end{array}$ & \multirow{2}{*}{$\mathrm{t}$} & Sig. \\
\cline { 2 - 5 } & $\mathrm{B}$ & Std. Error & Beta & & \\
\hline $1 \quad$ (Constant) & $-1,335$ & 2,010 & & & $-0,664$ & 0,508 \\
& Good University Governance & 0,127 & 0,051 & 0,252 & 2,469 & 0,015 \\
& 0,102 & 0,039 & 0,312 & 2,619 & 0,010 \\
$\quad$ Excellent Service & 0,001 & 0,001 & 0,362 & 2,251 & 0,027 \\
$\quad$ Good University & & & & &
\end{tabular}

Sumber: Data Penelitian, 2020

Berdasarkan Tabel 7, dapat dilihat nilai signifikan untuk variabel good university governance sebesar 0,015 kurang dari 0,05 $(0,015<0,05)$ dengan nilai koefisien positif 0,127 , sehingga $\mathrm{H}_{0}$ ditolak dan $\mathrm{H}_{1}$ diterima, dengan kata lain 
terdapat hubungan antara good university governance terhadap kepuasan mahasiswa. Penelitian sebelumnya telah membuktikan bahwa kepuasan mahasiswa dapat dipengaruhi Good University Governance. (Reny Arniwaty Lamadjido, 2012) menjelaskan bahwa semua variabel independen berpengaruh dengan variabel dependen. Transparansi berpengaruh terhadap kepuasan Pasien. Akuntabilitas berpengaruh terhadap kepuasan Pasien. Partisipasi berpengaruh terhadap kepuasan Pasien. Keadilan berpengaruh terhadap kepuasan Pasien. Kesimpulannya adalah akuntabilitas merupakan variabel yang paling berpengaruh terhadap kepuasan pasien.

Berdasarkan Tabel 7, dapat dilihat nilai signifikan untuk variabel Excellent Service sebesar 0,010 kurang dari 0,05 $(0,010<0,05)$ dengan nilai koefisien posititf 0,102, sehingga $\mathrm{H}_{0}$ ditolak dan $\mathrm{H}_{2}$ diterima, dengan kata lain terdapat hubungan antara Excellent Service terhadap Kepuasan Mahasiswa. Penelitian sebelumnya telah membuktikan bahwa kepuasan mahasiswa dapat dipengaruhi Excellent Service. (Silvia, 2012) menunjukkan bahwa kepuasan pelanggan di Kantor Pelayanan Perbendaharaan Negara (KPPN) Makassar II dipengaruhi oleh faktor pelayanan prima.

Berdasarkan Tabel 7, dapat dilihat nilai signifikan untuk variabel Good University Governance terhadap Kepuasan Mahasiswa dengan Excellent Service sebagai pemoderasi sebesar 0,027 kurang dari 0,05 $(0,027<0,05)$ dengan nilai koefisien positif 0,001 , sehingga $\mathrm{H}_{0}$ ditolak dan $\mathrm{H}_{3}$ diterima, dengan kata lain Excellent Service memperkuat pengaruh Good University Governance terhadap Kepuasan Mahasiswa. Hal ini berarti semakin meningkat Good University Governance dengan Excellent Service sebagai pemoderasi maka Kepuasan Mahasiswa akan semakin meningkat, sebaliknya semakin menurun Good University Governance dengan Excellent Service sebagai pemoderasi maka Kepuasan Mahasiswa akan semakin menurun.

\section{SIMPULAN}

Berdasarkan hasil pemaparan, diperoleh bahwa Good University Governance memiliki hubungan dengan Kepuasan Mahasiswa. Hal tersebut mengimplikasikan bahwa untuk memperoleh Kepuasan Mahasiswa yang maksimal maka pihak manajemen hendaknya memaksimalkan Good University Governance. Good Corporate Governance atau tata kelola yang baik merupakan pedoman yang sangat efektif digunakan untuk meningkatkan daya saing serta menciptakan pedoman pengelolaan. Dengan demikian maka Good Corporate Governance dapat ditingkatkan dengan cara meningkatkan pelayan terhadap mahasiswa dalam administrasi layanan, publisitas, dan transparansi. Selain itu, pemaparan diatas menunjukan bahwa Excellent Service memiliki hubungan dengan Kepuasan Mahasiswa. Hal tersebut mengimplikasikan bahwa untuk memperoleh Kepuasan Mahasiswa yang maksimal maka pihak manajemen hendaknya memaksimalkan Excellent Service. Excellent Service dalam penelitian ini adalah suatu sikap atau cara dalam melayani mahasiswa secara memuaskan. Dengan demikian Kepuasan Mahasiswa dapat dimaksimalkan dengan meningkatkan Excellent Service.

Berdasarkan penelitian yang telah dilakukan maka terdapat beberapa keterbatasan dalam penelitian ini. Hal tersebut berupa terbatasnya sampel yang 
digunakan yakni sebanyak 100 orang. Hal tersebut hendaknya diatasi dengan cara menambah sampel yang digunakan. Selain itu pada jurusan diploma hanya diwakilkan oleh tiga orang, hal ini menunjukkan skala data yang kecil dan belum dapat mewakilkan program diploma. Pada variabel good university governance, indikator kuisioner masih mengacu pada prinsip secara umum sehingga hal ini menjadi kelemahan bagi penelitian. Sedangkan untuk indikator pengukuran kuisioner pada variabel kepuasan terdapat bahasan jasa yang masih belum dapat dijelaskan oleh peneliti. Bagi peneliti selanjutnya jika ingin mereplikasi penelitian ini diharapkan menambah sampel penelitian serta menambah indikator pada kuisioner yang mengacu pada prinsip-prinsip Good University Governance.

\section{REFERENSI}

Delanty, G. (2002). The governance of universities: What is the role of the university in the knowled ge society? Canadian Journal of Sociology, 27(2), 185198. https:/ / doi.org/10.2307/3341710

Directorate of Institutional and Cooperation Ditjen Dikti Kemdikbud, 2014. (2014). Good University Governance (GUG). 45. staff.ugm.ac.id/atur/statuta/latih/2014/03GoodUniversityGovernance.pd $\mathrm{f}$

Ferlinda, E. D., Ribawanto, H., \& Siswidiyanto. (2018). Implementasi Good Corporate Governance dalam Meningkatkan Kualitas Pelayanan (Studi pada PT. Telkom Banyuwangi). Jurnal Administrasi Publik, 1(4), 25.

Hanifah. (2018). Good University Governance Analysis Implementation on Private University in West Java, Indonesia. International Conference of Organizational Innovation, 3(10), 1280-1288. https:/ / doi.org/10.18502/ kss.v3i10.3469

Hapsari, A. M., Kumadji, S., \& Abdilah, Y. (2015). Pengaruh Excellent Service terhadap Kepuasan Pelanggan serta Dampaknya pada Loyalitas Pelanggan ( Survei pada Pelanggan Pizza Hut Malang Town Square ). Jurnal Administrasi Bisnis, 1(2).

Jamal, A., \& Naser, K. (2002). Customer satisfaction and retail banking: An assessment of some of the key antecedents of customer satisfaction in retail banking. International Journal of Bank Marketing, 20(4), 146-160. https:/ / doi.org/10.1108/02652320210432936

Jamaluddin, \& Ruswanti, E. (2017). Impact of Service Quality and Customer Satisfaction on Customer Loyalty: A Case Study in a Private Hospital in Indonesia. IOSR Joumal of Business and Management, 19(05), 23-33. https:/ / doi.org/10.9790/487x-1905012333

Juiz, C., Guerrero, C., \& Lera, I. (2014). Implementing Good Governance Principles for the Public Sector in Information Technology Governance Frameworks. Open Journal of Accounting, 03(01), 9-27. https:/ / doi.org/10.4236/ojacct.2014.31003

Kuncaraningsih, H. S., \& Ridla, M. R. (2015). Good Corporate Governance Dalam Meningkatkan Kepuasan Muzzaki di Badan Amil Zakat Nasional. Jurnal MD Membangun Profesionalisme Keilmuan, 97-115.

Larasati, R., Asnawi, M., \& Hafizrianda, Y. (2018). Analisis Penerapan Governance Pada Perguruan Tinggi Di Kota Jayapura. Journal of Applied Manaferial Accounting, 2(2), 304-323. 
Putri, I. A. D. (2012). Peranan good corporate governance dan budaya terhadap kinerja organisasi. Jurnal Akuntansi E Bisnis, 7(2), 193-204.

Rahayu, S., \& Wahab, A. A. (2013). Pengaruh Penerapan Prinsip-Prinsip Good University Governance Terhadap Citra Serta Implikasinya Pada Keunggulan Bersaing Perguruan Tinggi Negeri Pasca Perubahan Status Menjadi BHMN (Survey Pada Tiga Pilar Perguruan Tinggi Negeri Berstatus BHMN di Jawa Bar. Jurnal Administrasi Pendidikan, 17(1), 154-173.

Reny Arniwaty Lamadjido. (2012). Penerapan Prinsip Good Corporate Governance terhdap kepuasan pasien di RSU Anutapurapalu Tahun 2013. Journal Ilmu Pemerintahan, 2(1), 67-78.

Rosyid, A., Fakhrina, A., \& Huda, M. (2015). SURVEI ATAS IMPLEMENTASI GOOD UNIVERSITY GOVERNANCE Studi Kasus STAIN Pekalongan. Jurnal Penelitian, 11(1). https:// doi.org/10.28918/jupe.v11i1.419

Ryynänen, S. P., \& Harisalo, R. (2018). A strategic and good governance perspective on handling patient complaints. International Journal of Health Care Quality Assurance, 31(8), 923-934. https:// doi.org/10.1108/IJHCQA-112016-0168

Silvia, F. (2012). Pelayanan Prima Dan Kepuasan Pelanggan Di Kantor Pelayanan Perbendaharaan Negara (KPPN) Makasar II. Jurnal Administrasi Negara, 112.

Widjajanti, K., \& Sugiyanto, E. K. (2015a). Gaya Kepemimpinan dan Good Governance Sebagai Upaya Peningkatan Excellent Service dan Kepercayaan Masyarakat. J. Dinamika Sosbud, 17(2), 270-284.

Widjajanti, K., \& Sugiyanto, E. K. (2015b). Good University Governance Untuk Meningkatkan Excellent Service Dan Kepercayaan Mahasiswa (Studi Kasus Fakultas Ekonomi Universitas Semarang). Jurnal Dinamika Sosial Budaya, 17(1), 69. https://doi.org/10.26623/jdsb.v17i1.504

Zattoni, A. (2007). Morten Huse: Boards, Governance and Value Creation: The Human Side of Corporate Governance. Journal of Management \& Governance, 11(4), 439-444. https:// doi.org/10.1007/s10997-007-9037-2

Zou, J. (2019). Improvement of Corporate Governance Structure and Implementation of Accounting Standards. Open Journal of Social Sciences, 07(01), 43-50. https:/ /doi.org/10.4236/jss.2019.71004 